\title{
Application of the design of experiments in the epoxidation process of 1,5,9- cyclododecatriene
}

\author{
Grzegorz Lewandowski, Jan Ćwirko \\ Szczecin University of Technology, Institute of Organic Chemical Technology, ul. Pułaskiego 10, 70-322 Szczecin, Poland, \\ e-mail: grzegorz.lewandowski@ps.pl
}

\begin{abstract}
An influence of the molar ratio of cis,trans,trans-1,5,9-cyclododecatriene to tert-butyl hydroperoxide, the concentration of the catalyst and the reaction time on the performance of the epoxidation process of cis,trans,trans-1,5,9-cyclodecatriene with tert-butyl hydroperoxide at the presence of molybdenum hexacarbonyl $\mathrm{Mo}(\mathrm{CO})_{6}$ was examined. Examinations were performed using statistical methods of the design of experiments. A mathematical model describing the influence of the parameters on conversion cis, trans,trans-1,5,9cyclododecatriene was obtained. An analysis of the data and rests was performed and an optimal value of conversion of cis,trans,trans-1,5,9-cyclododecatriene was established.
\end{abstract}

Keywords: epoxidation, design of experiments, 1,5,9-cyclododecatriene, optimization.

Presented at VII Conference Wasteless Technologies and Waste Management in Chemical Industry and Agriculture, Międzyzdroje, 12 - 15 June, 2007.

\section{INTRODUCTION}

The need for the knowledge, constant developing in scientific research and in industry but also the growing complexity of the examined objects needs a modern approach to the experimental studies. Because of this, there were worked out statistical methods of the design of experiments, which were based on the theory of probability and mathematical statistic, for example: fractional factorial designs, central composite designs, mixture designs, etc. ${ }^{1-3}$. To the most important advantages of these designs can be recognized theirs efficiency; it means the possibility to examine a large number of variables at a small number of experiments as well as presenting the dependency between the input and output variables in the form of a mathematical function ${ }^{4}$.

In the literature there is not enough information about comparing the quality of different methods of the design of experiments in practice, which could bring more information about the usefulness of the theoretically weaker and better designs under real conditions. Thus, the aim of this work is to perform a comparison of two plans: orthogonal and rotatable in the epoxidation of cis,trans,trans-1,5,9cyclododecatriene (CDT) using tert-butyl hydroperoxide (TBHP) over the molybdenum catalyst. As first, a rotatable design was realised for three input values: the molar ratio CDT/TBHP, the catalyst concentration and the reaction time.

\section{MATERIALS AND METHODS}

\section{Chemicals}

In the experiments there were used the $46 \%$ solution of TBHP in 1,2-dichloroethane (DCE), which was received in the extraction process of the $70 \%$ water solution of TBHP by DCE $^{5}$, CDT of the concentration $>98 \%$ from Sigma Aldrich, molybdenum hexacarbonyl, $\mathrm{Mo}(\mathrm{CO})_{6}$ of the concentration $>95 \%$ from Merck, and DCE from POCH S.A., Poland.

\section{Procedure}

All the experiments were performed according to the same procedure. A precisely weighed amount of CDT and the solution of TBHP in DCE was put into a three-necked flask of the capacity of $25 \mathrm{~cm}^{3}$, fitted with a thermometer, reflux and a mechanical stirrer. The flask was later immersed in an oil bath and the stirrer was started. When the temperature of the mixture reached $70^{\circ} \mathrm{C}$, the molybdenum catalyst dissolved in DCE was added quickly. The whole amount of raw materials was constant in all experiments and equal $18 \mathrm{~cm}^{3}$. After finishing the reaction, the flask with the post-reaction mixture was cooled immediately to room temperature to stop the reaction. The content of the flask was weighed and chromatographic and iodometry analyses were performed in order to calculate the mass balance.

The experiments were performed according to the rotatable design ${ }^{\mathbf{1}, \mathbf{6}}$. There were chosen three independent factors for the experiment: the molar ratio of CDT/TBHP $\left(\mathrm{X}_{1}\right)$, the concentration of $\mathrm{Mo}(\mathrm{CO})_{6}-$ catalyst $\left(\mathrm{X}_{2}\right)$, and the reaction time $\left(\mathrm{X}_{3}\right)$. The values of the factors in the normalized form $\left(\mathrm{x}_{\mathrm{i}}\right)$ and the related to them values in a real form $\left(\mathrm{X}_{\mathrm{i}}\right)$ are shown in Table 1. All the experiments were taken at the constant temperature of $70^{\circ} \mathrm{C} .20$ experiments altogether ( 8 in nucleus of the plan, 6 in star points and 6 in the centre of the plan) were performed for the three input values. The CDT $\left(\mathrm{K}_{\mathrm{CDT}}=\right.$ amount of reacted $\mathrm{CDT} /$ amount of introduced CDT) $\mathrm{x}$ 100) conversion was chosen as the answer function.

The design matrix of the experiments in the normalization form and the experimental results of the CDT conversion are shown in Table 2.

\section{RESULTS AND DISCUSSION}

\section{Data analysis}

First the experimental results were taken for a pre-analysis. The purpose of the pre-analysis was a proper identification of the structure and the quality of the received data.

The analysis of the basis statistics (Table 3 ) shows, that the smallest variability of the results has the subgroup, which contains 6 experiments (repetitions). The difference between the smallest and the largest value in the subgroup (range) is only $6.9 \%$. The variance for the repetitions is 5.7 
Table 1. The normalized and real values of the independent factors

\begin{tabular}{|c|c|c|c|}
\hline \multirow{2}{*}{$\begin{array}{c}\text { Value of factor } \\
\text { in normalized } \\
\text { form } \\
x_{i}\end{array}$} & \multicolumn{3}{|c|}{$\begin{array}{l}\text { Value of factor in real form } \\
\qquad X_{i}\end{array}$} \\
\hline & $\mathrm{X}_{1}[\mathrm{~mol} / \mathrm{mol}]$ & $X_{2}\left[\mathrm{~g} / \mathrm{cm}^{3}\right]$ & $\mathrm{X}_{3}$ [min.] \\
\hline-1 & 1 & $5,280 \cdot 10^{-4}$ & 20 \\
\hline 0 & 3 & $2,904 \cdot 10^{-3}$ & 70 \\
\hline 1 & 5 & $5,280 \cdot 10^{-3}$ & 120 \\
\hline
\end{tabular}

Table 2. The rotatable design experimental results

\begin{tabular}{|l|c|c|c|r|}
\hline Number of exper. & $\mathrm{X}_{1}$ & $\mathrm{X}_{2}$ & $\mathrm{X}_{3}$ & $\mathrm{~K}_{\mathrm{CDT}}, \%$ \\
\hline 1 & -1 & -1 & -1 & 19,22 \\
\hline 2 & -1 & -1 & 1 & 38,81 \\
\hline 3 & -1 & 1 & -1 & 26,22 \\
\hline 4 & -1 & 1 & 1 & 45,97 \\
\hline 5 & 1 & -1 & -1 & 9,94 \\
\hline 6 & 1 & -1 & 1 & 12,93 \\
\hline 7 & 1 & 1 & -1 & 9,71 \\
\hline 8 & 1 & 1 & 1 & 23,22 \\
\hline 9 & $-1,682$ & 0 & 0 & 57,53 \\
\hline 10 & 1,682 & 0 & 0 & 8,48 \\
\hline 11 & 0 & $-1,682$ & 0 & 8,39 \\
\hline 12 & 0 & 1,682 & 0 & 25,84 \\
\hline 13 & 0 & 0 & $-1,682$ & 6,52 \\
\hline 14 & 0 & 0 & 1,682 & 30,95 \\
\hline $15(\mathrm{C})$ & 0 & 0 & 0 & 21,99 \\
\hline $16(\mathrm{C})$ & 0 & 0 & 0 & 25,41 \\
\hline $17(\mathrm{C})$ & 0 & 0 & 0 & 26,16 \\
\hline $18(\mathrm{C})$ & 0 & 0 & 0 & 27,20 \\
\hline $19(\mathrm{C})$ & 0 & 0 & 0 & 28,89 \\
\hline $20(\mathrm{C})$ & 0 & 0 & 0 & 27,60 \\
\hline $1 \mathrm{C})$ & 0 & 0 & & \\
\hline
\end{tabular}

(C) - centre of plan, experiments $15-20$

and is over 30 times less than the variance calculated for all the results. The average values in groups 14 and 20 of the experiments are similar, but in the group of 6 experiments (repetitions) some deviations to higher values are observed.

The correlation coefficients of the CDT conversion with independent variables were presented in Table 4. It follows from Table 4 that the molar ratio of the CDT/TBHP and conversion of CDT are highly negatively correlated (-0.74). Such good correlation partly results from the way of counting of the CDT conversion, where in the calculating formula the number of moles of CDT is inserted. The reaction time is also strongly connected with the CDT conversion (strong positive correlation). However, there is lack of significant correlation of the catalyst concentration with the conversion of CDT.

\section{The analysis of variance ${ }^{7,8}$}

In Table 5 parts of each input variable in the sum of squares (SS), were presented, it means their parts in the whole variability of the output values. Mean squares are distributed well among the variables. Pure error does not differ statistically from the error of fit, which means, that the regression equation containing all the variables from Table 5 will be statistically adequate. It is also seen that line effects have a significant influence on the $\mathrm{K}_{\mathrm{CDT}}$ value, mainly the molar ratio $\left(\mathrm{x}_{1}\right)$ and the reaction time $\left(\mathrm{x}_{3}\right)$.
Table 4. The correlation coefficient (calculated from the real values)

\begin{tabular}{|c|c|c|c|}
\hline & $\mathrm{X}_{1}$ & $\mathrm{X}_{2}$ & $\mathrm{X}_{3}$ \\
\hline $\mathrm{K}_{\mathrm{CDT}} \%$ & $\mathbf{- 0 , 7 4}$ & 0,25 & $\mathbf{0 , 4 6}$ \\
\hline
\end{tabular}

(bold coefficients are important with probability $\alpha=0.05$ )

\section{Mathematical model for the CDT conversion}

Variables in Table 5, whose coefficients $b_{i}$ are in bold were taken in the mathematical model describing an influence of the three input variables: the molar ratio of CDT/ TBHP, the catalyst concentration and the reaction time on the CDT conversion. For the CDT conversion, the regression equation is in a square form:

$\mathrm{Y}_{K C D T}=26,18-11,49 x_{1}+2,52 x_{1}^{2}+3,92 x_{2}-3,1 x_{2}^{2}+7,1 x_{3}$

$$
-2,57 x_{3}^{2}-2,85 x_{1} x_{3}
$$

The regression equation for the CDT conversion is adequate (Table 5) and has a high value of a coefficient of multiple correlation $\mathrm{R}^{2}(>90 \%)$ for a confidence interval at the level of $95 \%$.

\section{Research of the model: rests $^{8,9}$}

The diagnostics of a built approximation function relies mainly on testing the rests. The rests contain this part of the variation of the CDT conversion, which a received function does not explain.

Testing of the rests was performed graphically. A test of normality of rest distributions and rest distributions according to a sequence of time, was performed. In order to do this a histogram of rest normalities (Figure 1) was made and the Shapiro-Wilk test of normality was performed. It turned out that the distribution of rests exhibits normal character. The determined minimum, maximum, range and the variation values for the rests were shown in Table 6.

In Figure 2 there was shown a range of rests according to a sequence of time, which means, in the order of performing the experiments. The largest deviation from the centre can be observed in experiments 5 and 10. Apart from the pointed exceptions, the rests in the other experi-

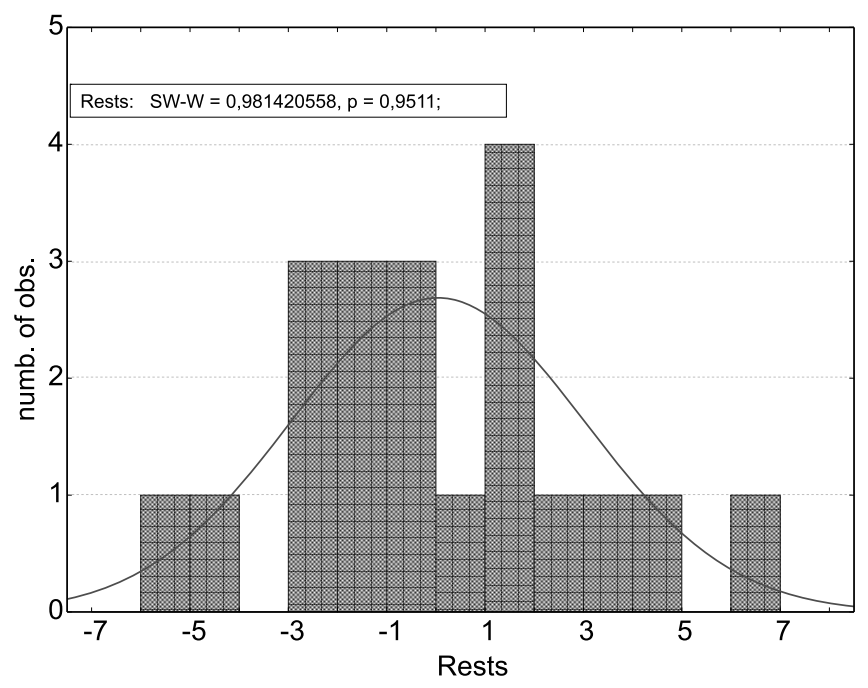

Figure 1. Range of normality of rests (in the box - results of Shapiro-Wilk test)

Table 3. Basic statistics calculated on the base of the results of the CDT conversion

\begin{tabular}{|l|c|c|c|r|r|r|}
\hline & Average & Min. & Max. & Range & Variation & Dev.Std \\
\hline $\mathrm{K}_{\mathrm{CDT}} \%$ (20 experiments) & 24.0 & 6.5 & 57.5 & 51.0 & 172.6 & 13.1 \\
\hline $\mathrm{K}_{\mathrm{CDT}} \%$ (6 repetitions) & 26.2 & 22.0 & 28.9 & 6.9 & 5.7 & 2.4 \\
\hline $\mathrm{K}_{\mathrm{CDT}} \%$ (14 experiments) & 23.1 & 6.5 & 57.5 & 51.0 & 246.9 & 15.7 \\
\hline
\end{tabular}


Table 5. The analysis of variance

\begin{tabular}{|l|r|r|r|r|r|r|r|}
\hline & Effects & \multicolumn{1}{|c|}{$\mathrm{b}_{\mathrm{i}}$} & $\mathrm{SS}$ & $\mathrm{df}$ & $\mathrm{MS}$ & $\mathrm{F}$ & $\mathrm{P}$ \\
\hline $\mathrm{X}_{1}$ & $-22,98$ & $\mathbf{- 1 1 , 4 9}$ & 1803,2 & 1 & 1803,2 & 316,1 & 0,00001 \\
\hline $\mathrm{X}_{2}$ & 7,85 & $\mathbf{3 , 9 2}$ & 210,1 & 1 & 210,1 & 36,8 & 0,00175 \\
\hline $\mathrm{X}_{3}$ & 14,24 & $\mathbf{7 , 1 2}$ & 687,6 & 1 & 687,6 & 120,5 & 0,00011 \\
\hline $\mathrm{x}_{1}{ }^{2}$ & 5,03 & $\mathbf{2 , 5 2}$ & 91,3 & 1 & 91,3 & 16,0 & 0,01031 \\
\hline $\mathrm{x}_{2}{ }^{2}$ & $-6,20$ & $\mathbf{- 3 , 1}$ & 138,6 & 1 & 138,6 & 24,3 & 0,00436 \\
\hline $\mathrm{X}_{3} \mathrm{x}_{1} \mathrm{X}_{2}$ & $-5,14$ & $\mathbf{- 2 , 5 7}$ & 92,6 & 1 & 92,6 & 16,2 & 0,01004 \\
\hline $\mathrm{X}_{1} \mathrm{X}_{3}$ & $-1,03$ & $-0,51$ & 2,1 & 1 & 2,1 & 0,4 & 0,56902 \\
\hline $\mathrm{X}_{2} \mathrm{X}_{3}$ & $-5,71$ & $\mathbf{- 2 , 8 5}$ & 65,2 & 1 & 65,2 & 11,4 & 0,01963 \\
\hline Lack of fit & 2,67 & 1,33 & 14,3 & 1 & 14,3 & 2,5 & 0,17451 \\
\hline Pure error & & 122,6 & 5 & 24,5 & 4,3 & 0,06774 \\
\hline Total sum of Squares (SS) & & 28,5 & 5 & 5,7 & & \\
\hline
\end{tabular}

SS - Sum of Squares, df - degrees of freedom, MS - Mean Square, F - distribution, $p$ - values of probability calculated for F -statistics

Table 6. Basic statistics for the rests

\begin{tabular}{|l|c|c|c|c|c|c|}
\hline & Av & Med. & Min. & Max. & Range & Variation \\
\hline CDT conversion & 0,0 & $-0,342$ & $-5,5$ & 6,58 & 12,09 & 8,82 \\
\hline
\end{tabular}

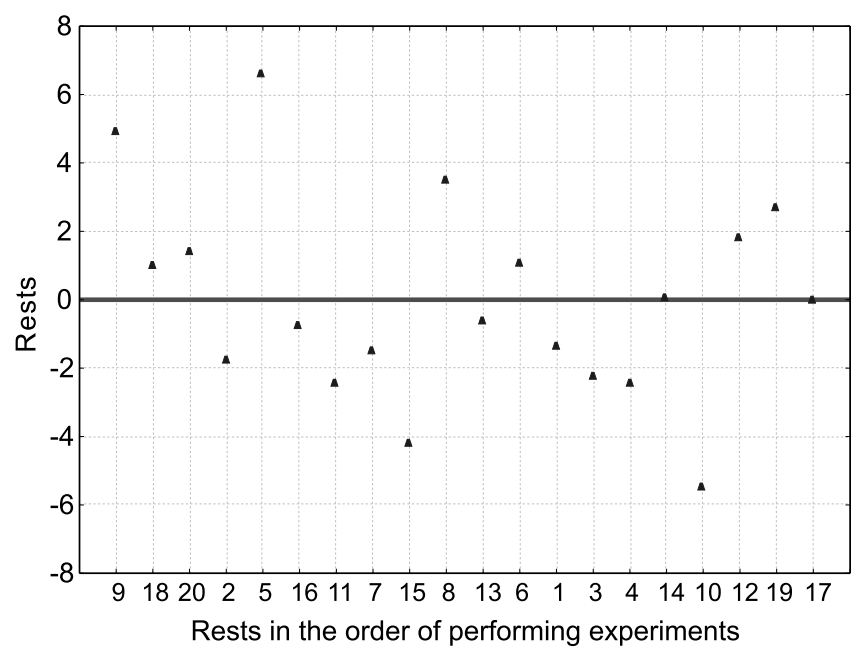

Figure 2. A range of rests according to the order of time

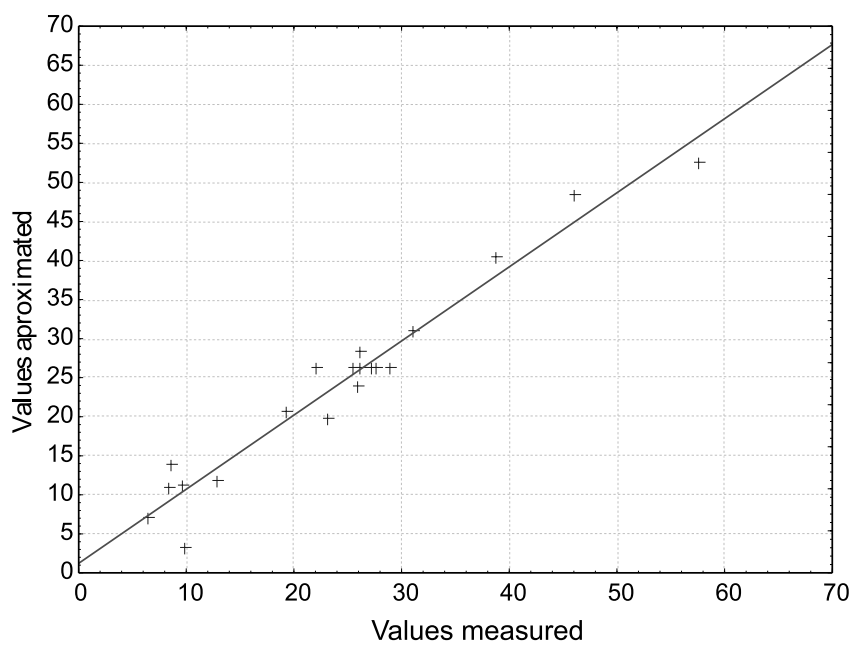

Figure 3. The values measured in the experiments related to the approximate from a certain function for the CDT conversion

ments are spaced uniformly along the central line. It is confirmed by the constancy of the variance of the answer function.

The approximated values approach the real values (Figure 3) quite well. A matching line drawn through these points is at the $45^{\circ}$ angle. Bigger deviations are seen at the smaller values of the functions.
The approximated function of the CDT $\left(Y_{K_{C D T}}\right)$ conversion contains all the main variables which influence its value. Only two interactions $\left(x_{1} x_{2}\right.$ and $\left.x_{2} x_{3}\right)$ turned out to be not important statistically, thus they were not put into the model. The maximum value of the function $Y_{K_{C D T}}=66,47 \%$, was received with the following values of the input factors: the molar ratio of CDT/TBHP $=1$, the $\mathrm{Mo}(\mathrm{CO})_{6}$ catalyst concentration $=0,004092$ and reaction time $120 \mathrm{~min}$.

The influence of the studied process parameters on the CDT conversion was presented by the isoline diagram. For the molar ratio of $\mathrm{CDT} / \mathrm{TBHP}=1$ and the reaction time $=120 \mathrm{~min}$, the change of the catalyst concentration in the whole range from 0,000528 to $0,00528 \mathrm{~g} / \mathrm{cm}^{3}$ influences on the CDT conversion, which can take high values under such conditions from 50.0 to $66.7 \%$ (Figure 4). An increase in the molar ratio of CDT/TBHP from 1 to 5 , at the optimum catalyst concentration, causes a decrease in conversion to about $12 \%$. The calculated values of the CDT conversion are partly correlated to the molar ratio of CDT/TBHP.

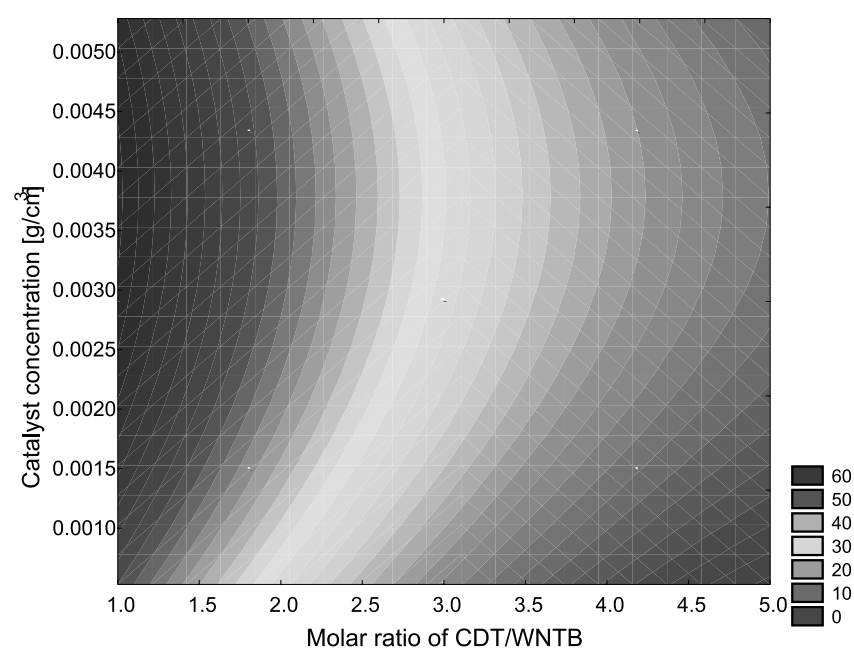

Figure 4. The influence of the molar ratio of CDT/TBHP and the catalyst concentration on the CDT conversion (reaction time $=120 \mathrm{~min}$.)

The CDT conversion increases with the rise in the reaction time (Figure 5). The largest values of $\mathrm{K}_{\mathrm{CDT}}(>57 \%$ ) were obtained for the reactions time in the range from 80 to 120 minutes and for the molar ratio of CDT/TBHP = 1. It follows from Figures 5 and 6 that higher values of conversion can be received by extending the reaction time to $120 \mathrm{~min}$. 


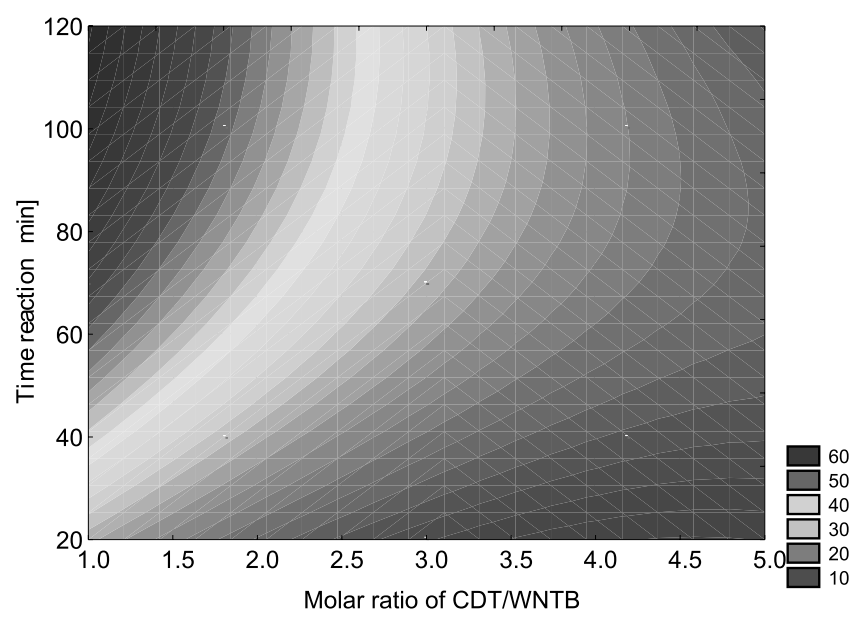

Figure 5. The influence of the molar ratio of CDT/TBHP and the reaction time on the $\mathrm{CDT}$ conversion (catalyst concentration - 0,004092 $\mathrm{g} / \mathrm{cm}^{3}$ )

For the smallest $\mathrm{Mo}(\mathrm{CO})_{6}$ catalyst concentration $\left(0,000528 \mathrm{~g} / \mathrm{cm}^{3}\right)$ and the maximum value of the reaction time (120 $\mathrm{min})$ and the equimolar ratio of CDT/TBHP, the values of the CDT conversion are higher than $40 \%$ (Figure 6 ). Shortening of the reaction time to 20 minutes, at the same catalyst concentration, reduces the CDT conversion to about $10 \%$. An increase in the catalyst concentration to the optimum value at the reaction time -120 min increases a degree of the reacted CDT to $66,5 \%$, then a slight decrease of conversion happens.

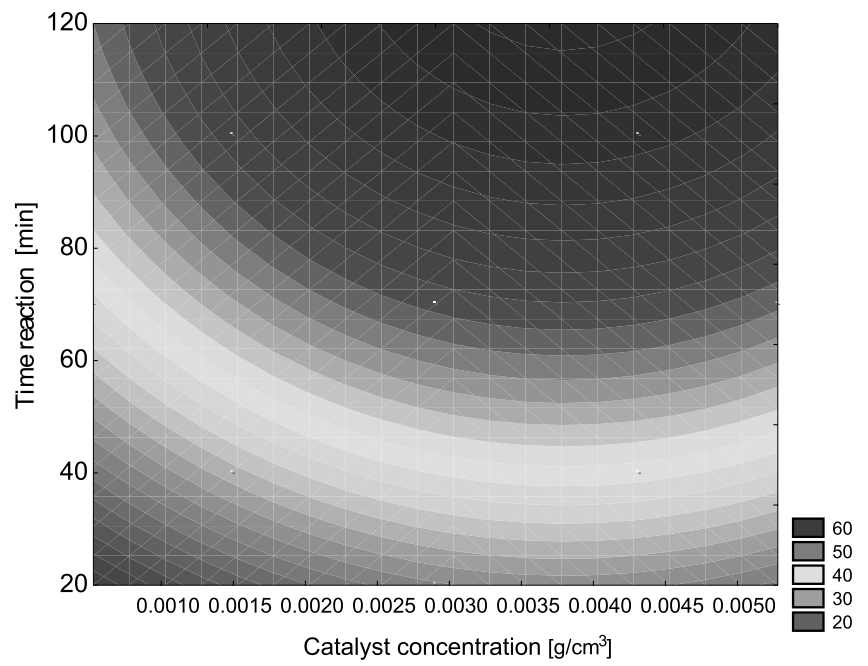

Figure 6. The influence of the catalyst concentration and the reaction time on the $\mathrm{CDT}$ conversion (molar ratio of $\mathrm{CDT} / \mathrm{TBHP}=1$ )

The biggest positive influence on the value of the CDT conversion has the low molar ratio of CDT/TBHP, the long reaction time and the high catalyst concentration.

\section{CONCLUSIONS}

The influence of the molar ratio of CDT/TBHP, the catalyst concentration and the reaction time on the CDT conversion was described by a statistic method of the design of experiments. The received predicative model is well fitted to the real data, which was proved by testing the rests, where no serious deviation was seen. The maximum value of the $Y_{K_{C D T}}=66,47 \%$ function was received at the following values of the input variables: the molar ratio of
$\mathrm{CDT} / \mathrm{TBHP}=1$, the $\mathrm{Mo}(\mathrm{CO})_{6}$ catalyst concentration $=$ 0,004092 and the reaction time $120 \mathrm{~min}$. It was shown that the low molar ratio of CDT/TBHP, the high catalyst concentration and the long reaction time have positive influence on the CDT conversion.

\section{LITERATURE CITED}

(1) Fisher R. A.: Design of experiments, Oliver \& Boyd, London, 1935.

(2) Mańczak K.: Technika planowania eksperymentu,

WNT, Warszawa, 1976.

(3) http://www.statsoft.com/textbook/stathome.html.

(4) Polański Z.: Planowanie doświadczeń w technice, PWN, Warszawa, 1984.

(5) Sharpless K. B., Verhoeven T. R.: Metal catalysed, highly selective oxygenation of olefins and acetylenes with tert-butyl hydroperoxide. Practical consideration and mechanisms, Aldrichim. Acta, 1979, 12, 63 - 74.

(6) Montgomery D. C.: Design and analysis of experiments, John Wiley \& Sons Inc., 2005.

(7) Czermiński J. B., Iwasiewicz A., Paszek Z., Sikorski A.: Metody statystyczne dla chemików, PWN, Warszawa, 1992.

(8) Draper N. R., Smith H.: Applied regression analysis, John Wiley \& Sons Inc, 1998.

(9) Jobson J. D.: Applied multivariate data analysis, Springer-Verlag, New York, 1991. 